\title{
Teens' Social Media Use and Collective Action
}

\author{
Hyunjin Seo, Ph.D.* \\ School of Journalism and Mass Communications, University of Kansas \\ hseo@ku.edu \\ J. Brian Houston, Ph.D. \\ Department of Communication, University of Missouri-Columbia
}

Leigh Anne Taylor Knight, Ed.D.

KC-AERC Executive Director

Emily J. Kennedy, M.A.

KC-AERC Project Coordinator, University of Kansas

\author{
Alexandra B. Inglish \\ School of Journalism and Mass Communications, University of Kansas
}

*Corresponding Author

Manuscript accepted for publication in New Media \& Society 


\title{
Teens' Social Media Use and Collective Action
}

\begin{abstract}
This research examined how social self-efficacy, collective self-esteem, and need to belong can be used to predict teens' use of social media. The particular focus was on how these social psychological variables together with social media use account for variation in teens' participation in a flash mob-an exemplar of $21^{\text {st }}$-century collective action. Empirical data come from a survey of teens in a major Midwestern city in the USA. Teens' need to belong was positively associated with the amount of time they reported spending on social networking sites even when controlling for gender, race, and household socio-economic status. Both teens' social self-efficacy and time spent on YouTube were positively associated with their intention to participate in a flash mob in the future. These and other findings are discussed in the context of the role of social media in youth culture and collective action.
\end{abstract}

Keywords: flash mob, social media, teen, collective action, self-efficacy, need to belong, collective self-esteem 
Social Media \& Collective Action 2

\section{Teens' Social Media Use and Collective Action}

\section{Introduction}

The wide availability of digital media has influenced the ways teens build and maintain social networks as well as how they consume and share information. According to surveys of US teens by the Pew Research Center, the proportion of teens with Internet access has increased from $87 \%$ in 2004 to $95 \%$ in 2012, and the proportion of teens engaging in some form of social media usage has increased from 55\% in 2006 to 83\% in 2012 (Brenner, 2013; Lenhart et al., 2011; Lenhart, 2012; Madden et al., 2013; Purcell, 2012). Social media refers to Internet-based applications that allow people to create and exchange content using digital network technologies (boyd and Ellison, 2008; Kaplan and Haenlein, 2010). Online behavior of these digital nativesthe generation born after the general introduction of digital technologies and that has grown up immersed in and familiar with those technologies-has been studied in many different contexts including civic engagement, identity, and social inclusion (e.g., Bennett, Wells and Freelon, 2011; Hundley and Shyles, 2010; Ito et al., 2010; Ledbetter et al., 2011; Lenhart et al., 2011; Palfrey and Gasser, 2008).

A relatively recent question at the intersection of youth and social media is how teens are using social media to facilitate planning and organizing flash mobs. A flash mob is a gathering of people who assemble in a public place, carry out a brief predetermined public performance, and then quickly disperse (Goldschmidt, 2011; Wasik, 2011). The flash mob is an important cultural phenomenon, as it has become a popular form of collective action that has been facilitated by widely available and accessible digital communication tools (Bimer, Flanagin and Stohl, 2012; Earl and Kimport, 2011; Kahn and Kellner, 2004; Rheingold, 2002). Examples of recent flash mobs range from "Social Mob 4 Good" aimed at drawing attention to the challenges facing local 
social service agencies in the United States (CNN, 2010) to the London Olympics flash mob at Wimbledon (BBC, 2012).

As with other forms of collective action, flash mobs occasionally have taken a violent turn. For example, gunfire injured three people when hundreds of teens gathered for a late-night flash mob at an upscale shopping area in Kansas City, Missouri, in summer 2011. Philadelphia and Boston faced similar problems with a series of flash mob gatherings turning violent. These events have led to a recognition that flash mobs need to be better understood (Goldschmidt, 2011; Urbina, 2010; Wasik, 2011).

The research reported here is aimed at analyzing how teens' social media use and social psychological characteristics are associated with their participation or interest in flash mobs. In spring 2012, the authors conducted a survey of teens living in Kansas City, Missouri. Survey items covered teens' understandings and experiences with flash mobs, how teens reported using social media to organize such gatherings, and a variety of demographic and social psychological variables including social self-efficacy and collective self-esteem. Social self-efficacy refers to how competent an individual feels in forging new relationships (Zullig, Teoli and Valois, 2011), whereas collective self-esteem is related to the level of attachment one has to a social group (Baker, 2009; Crocker and Luhtanen, 1990; Tajfel, 1981).

Theoretical and operational linkages investigated in this study are useful for those who study teens' behavior, group identity, and collective action. In addition, the findings reported here can help policymakers identify more effective ways to encourage teens in this age of social media and online social networking. 


\section{Teens, Social Media, and Social Psychology}

Social media has emerged as important forms of communication among teens in the United States (Duggan and Brenner, 2013; Ito et al., 2010; Lenhart et al., 2011; Lenhart, 2012; Purcell, 2012). More than $95 \%$ of teens used the Internet in 2012, and about $83 \%$ of teen Internet users reported using social media in 2012 - an increase from 55\% in 2006 (Brenner, 2013; Lenhart, 2012, Purcell, 2012). In this paper, social media refers to Internet-based applications that allow people to create and exchange content using digital network technologies (boyd and Ellison, 2008; Kaplan and Haenlein, 2010). Facebook is the dominant social media site among teens with 93\% of teen social media users having an account with Facebook, according to 2012 reports (Lenhart, 2012; Purcell, 2012). Texting is the most preferred method of communication among teens (63\%), and about $30 \%$ of teens consider social networking sites an important communication method.

While youth's use of the Internet varies (Hargittai and Hinnant, 2008; Hundley and Shyles, 2010), research suggests that the majority of teens have generally positive interactions online and find a sense of social inclusion through sharing information with peers in the digital sphere (boyd, 2008; Ito et al., 2010; Lenhart et al., 2011). The opportunity for perceived positive experiences and connectedness available through online communication renders social media a popular vehicle for teens to communicate, plan events, and meet new people. Previous studies suggest that teens find social media sites provide a place they can call home-their personal, though not private, digital space to express themselves (boyd, 2008; Correa, Hinsley and De Zuniga, 2010; Davis, 2011; Ellison, Steinfield and Lampe, 2007; Ledbetter et al., 2011). For example, Ellison et al.'s (2007) study shows that young adults' use of Facebook is positively associated with the maintenance and creation of social capital. Their research, based on a survey 
of undergraduate students, also suggests that Facebook usage may benefit users with low selfesteem and low life satisfaction.

Personality traits of teens or young adults have been shown to influence their social media use or online social behavior (Baker, 2009; Correa et al., 2010; Hlebec, Manfreda and Vehovar, 2006; Ledbetter, et al., 2011; Pelling and White, 2009; Valkenburg and Peter, 2008). Based on an online survey of U.S. young adults, Correa et al. (2010) found that extraversion and openness to experiences were positively associated with social media use. In comparison, young adults' emotional stability was negatively associated their social media use controlling for sociodemographics and life satisfaction.

Baker (2009) examined adolescents' motivations for using social networking sites with a particular emphasis on group identification and collective self-esteem. Group identification refers to a member's identification with an interacting group, and collective self-esteem is defined as an individual's self-concept derived from his/her "knowledge of membership in a social group together with the value and emotional significance attached to that membership" (Baker, 2009; Crocker and Luhtanen, 1990; Tajfel, 1981: 255). According to Barker's study (2009) of adolescents, those reporting high group identification and positive collective selfesteem tended to use social networking sites mainly for contact with their closest peer groups. In comparison, adolescents reporting negative collective self-esteem tended to seek a form of virtual companionship or social compensation through engaging in social networking sites. This can be explained from the perspective of social identity gratifications which emphasizes opportunities to identify with in-group members who look and act similarly to each other as well as to compare themselves to out-group members (Harwood, 1999; Hlebec et al., 2006). 
Teens' online social behavior has also been found to be associated with level of loneliness and need to belong (Ledbetter, et al., 2011; Pelling and White, 2009; Valkenburg and Peter, 2008). In social psychology, need to belong refers to the motivation to be associated with others and to be accepted by them. Research has found that compared with non-lonely adolescents, lonely adolescents are more likely to experiment with their identities online by leveraging the relative anonymity of the Internet to learn how to interact with people (Valkenburg and Peter, 2008). For example, lonely adolescents may visit chat rooms to practice relationship formation skills and to overcome shyness by examining how people react to them online.

Social networking sites potentially satisfy teens' need for belonging. While these sites offer diverse features, people are drawn to them primarily for personal connections and sharing of their activity with a growing number of "friends" (boyd, 2008; Ito et al., 2010; Ledbetter et al., 2011; Pelling and White, 2009). A survey of college students indicated a positive relationship between need to belong and attitude toward social networking sites (Gangadharbatla, 2008). These social psychological factors-collective self-esteem, need to belong, and social selfefficacy-may help us better understand why and how and teenagers use social media for flash mobs.

\section{Flash Mobs and Youth Collective Action}

Teens' increased use of social media has important implications for collective action. Studies have shown that digital communication technologies have facilitated mobilization of individuals seeking common goals-whether civic or non-civic (Bimer, Flanagin and Stohl, 2012; Earl and Kimport, 2011; Rheingold, 2002). For example, Bimer, Flanagin and Stohl pointed out that wide availability of and accessibility to communication technologies has "altered the 
structure as and forms of collective efforts today toward the direction of enhanced individual agency" (2012: 3). Indeed, these changes are in line with the emergence of more general decentralization and disintermediation as properties of the networked information society (Benkler, 2006; Castells, 2002).

A flash mob is a form of collective action that has been organized mainly via social media or mobile communication devices. For the purpose of this research, a flash mob is defined as a gathering of citizens who assemble in a public place, carry out a predetermined action, and then quickly disperse (Goldschmidt, 2011; Gore, 2010; Lee, 2011; Molnar, 2009; Walker, 2003; Wasik, 2011). A sudden appearance of hundreds of people at a New York Macy's in 2003 is widely considered as the first flash mob in the current context (Wasik, 2011). Some have suggested classifying flash mobs into different types (Molnar, 2009; Gore, 2010). For example, Molnar (2009) identified five types of flash mob based on function. They are (i) atomized flash mobs which are original, apolitical, and fun; (ii) interactive flash mobs which are organized often to reclaim public spaces and related to the urban playground movement - collective activities arranged via Internet-based communication tools to redeem urban spaces; (iii) performance flash mobs involving carrying out brief dancing, musical, or other artistic activities; (iv) political flash mobs aimed at promoting a social agenda; and (v) advertising flash mobs used by companies to raise awareness of their brands.

Another widely used term in this area is smart mobs (Rheingold, 2002). One of the most important characteristics of smart mobs is a clear social purpose. While previous studies have examined how technologies are used to organize smart mobs (Kahn and Kellner, 2004; Pickard, 2008; Biddix and Park, 2008), little research has been done to examine the role of new 
technologies in organizing flash mobs of non-overtly political nature. The current research attempts to fill the gap.

There are several reasons why studying youth participation in flash mobs is important. The first reason relates to the role of new digital technologies in flash mobs. Ranging from dancing performances and pillow fights to service acts aimed at helping others in need, flash mobs have a common connecting thread-they are organized, planned, and executed via social networking or mobile communication devices (Goldschmidt, 2011; Rheingold, 2002; Walker, 2003; Wasik, 2011). With the emergence of mobile and digital communication tools, Rheingold predicted that "the combination of computation, communication, reputation and location awareness" might lead to "cooperation epidemics" or an insurgence of smart mobs (2002: 169170). In recent flash mobs, text messaging and social media have played an important role in spreading word about proposed action and encouraging the crowd to participate in that action (Wasik, 2011). Research on flash mobs among teens in connection with their social media use provides an important opportunity to understand how the interplay of flash mobs and social media may influence youth culture.

Second, there are important social psychological and behavioral aspects of youth that can be studied through flash mobs. For example, participants in flash mobs often build shared identities, as suggested by Wasik, "What seems like anarchic behavior is in fact governed by a shared self-conception and thus a shared set of grievances" (Wasik, 2011, para. 3). While flash mobs may appear pointless and spontaneous to observers, they generally make sense to those who are part of the performances. Like other mass gatherings, a flash mob requires seed behavior and a degree of personal engagement (Zeitz, Tan and Zeitz, 2009). There should be an individual or a group of people who serves as the seed by engaging the crowd to take action. 
Finally, studying flash mobs may suggest clues as to how to better involve teens in positive community and civic collective activities. Bennett and his colleagues discussed a shift from dutiful citizenship to actualizing citizenship in identifying a new civic paradigm (Bennett, Wells and Rank, 2009; Bennett, Wells and Freelon, 2011). They argue that this change reflects "a generational shift from taking cues as members of groups or out of regard for public authorities (opinion leaders, public officials, and journalists), and toward looser personal engagement with peer networks that pool (crowd source) information and organize civic action using social technologies that maximize individual expression" (Bennett, Wells and Freelon, 2011: 839). In fact, this argument is closely related to the observation that the emergence of digital communication technologies has lowered the "threshold for the collective action" (Bimer, Flanagin and Stohl, 2012; Earl and Kimport, 2011; Rheingold, 2002). Compared with the industrial information society that relied on capital intensive and professional production, the networked information society has enabled a new environment by empowering individuals to actively create and share content and information rather than merely being passive information consumers (Benkler, 2006; Castells, 2002). Thus the flash mob phenomenon can be examined through the lens of collective action in this digital media age. It should be noted here that not all collective action is civic and not all civic activities are collective.

\section{Research Questions and Hypotheses}

Based on the preceding literature review, the following research question and hypotheses are examined in this study. The tested theoretical model considering these variables is shown in Figure 1.

Research Question 1: How are social media used by teens to obtain information about a flash mob? 
Hypothesis 1: Teens' social psychological characteristics influence the amount of time they spend on social networking sites even when controlling for gender, race, and household socio-economic status.

Hypothesis 1a: Teens' social self-efficacy has a positive effect on the amount of time they spend on social networking sites even when controlling for gender, race, and household socioeconomic status.

Hypothesis 1b: Teens' collective self-esteem has a positive effect on the amount of time they spend on social networking sites even when controlling for gender, race, and household socio-economic status.

Hypothesis 1c: Teens' need to belong has a positive effect on the amount of time they spend on social networking sites even when controlling for gender, race, and household socioeconomic status.

Research Question 2: How is teens' stated intention to participate in a flash mob associated with their social media use when controlling for the demographic variables (gender, race, and household socio-economic status) and social psychological variables (social self-efficacy, collective self-esteem, and need to belong)?

Research Question 3: How are teens' social psychological characteristics (social self-efficacy, collective self-esteem, and need to belong) associated with their intention to participate in a flash mob?

\section{Method}

A survey of Kansas City youth aged 13-19 was conducted in March 2012 to examine use of social media, understandings of flash mobs, and social psychological and demographic characteristics. An initial survey questionnaire was developed based on a review of the literature 
discussed earlier (e.g., Davis, 2011; Ledbetter, et al., 2011; Pelling and White, 2009; Valkenburg and Peter, 2008; Valkenburg, Schouten and Peter, 2005) and further refined through focus groups with 50 Kansas City youth. The authors next conducted a pretest of the questionnaire on a sample of 18 youth recruited through a teen-oriented radio station. The participants in the survey pretest were asked to complete the survey and then to identify questions, answer choices, or statements that were ambiguous or difficult to comprehend. Based on their feedback, several questions or statements were rephrased to enhance their clarity and some answer options were added. The final survey questionnaire included a total of 30 questions in a mostly close-ended format.

The online survey was created on Qualtrics.com, one of the leading online survey tools. A paper-and-pencil version of the survey (in both English and Spanish), which included the same set of questions and similar layouts, was created for teens that might not have access to the online version of the survey. Survey respondents were recruited through schools, youth centers, and a youth-oriented radio broadcast. Youth under the age of 18 were required to submit signed parental and youth informed written consent forms prior to participating in the survey.

Survey participants were told the study would deal with use of the Internet and social gatherings and that responses would remain confidential and be read only by the researchers. They were also informed that participation in the survey was voluntary and that they could stop participation at any time. Completing the questionnaire took 10-15 minutes. The survey was in the field for four weeks.

\section{Measured Variables}

Social Psychological Variables. The survey examined social psychological variables including social self-efficacy, collective self-esteem, and need to belong. Previous research 
guided the measurement of these concepts (e.g., Baker, 2009; Gangadharbatla, 2008; Harwood, 1999; Hlebec, Manfreda and Vehovar, 2006; Ledbetter, et al., 2011; Pelling and White, 2009; Valkenburg and Peter, 2008; Zullig, Teoli and Valois, 2011). Prior questions were adapted to make them more relevant to this study.

Eight items were used to measure a participant's social self-efficacy. Social self-efficacy refers to individuals' belief that they are competent in forging new friendships (Zullig, Teoli and Valois, 2011). The items were adapted from Zullig et al.'s study (2011) of US adolescents. Those items included: (i) "How well can you express your opinions when friends or classmates disagree with you?"; (ii) "How well can you become friends with other people your age?"; (iii) "How well can you have a chat with an unfamiliar person?"; (iv) "How well can you work in harmony with your classmates or co-workers?"; (v) "How well can you tell other people your age that you are doing something they don't like?"; (vi) "How well can you tell a funny story to a group your age?”; (vii) "How well do you succeed in staying friends with people your age?"; and (viii) "How well do you succeed in preventing quarrels with other people your age?" The reliability of the resulting scale was tested by Cronbach's alpha, the most widely used measure of reliability, and the value was .87 .

Collective self-esteem is defined as an individual's self-concept derived from his/her "knowledge of membership in a social group together with the value and emotional significance attached to that membership" (Baker, 2009; Crocker and Luhtanen, 1990; Tajfel, 1981: 255). In this survey, the following items were used to measure participants' collective self-esteem: (i) "I am a worthy member of the groups or organizations I belong to"; (ii) "I often regret that I belong to some of the groups or organizations I do"; (iii) "Overall, my groups or organizations are considered good by others"; (iv) "Overall, my group or organization memberships have very 
little to do with how I feel about myself”; (v) "I feel I don't have much to offer to the groups or organizations I belong to"; (vi) "In general, I am glad to be a member of the groups or organizations I belong to"; (vii) "Most people consider my groups or organizations, on the average, to be more ineffective than other groups or organizations"; (viii) "The groups or organizations I belong to are an important reflection of who I am"; (ix) "I am a cooperative participant in the groups or organizations I belong to"; and (x) "Overall, I often feel that the groups or organizations of which I am a member are not worthwhile.” Cronbach's alpha for this index was .81 .

"Need to belong" is another social psychological variable examined in this research given its implications for teens' online behavior (Gangadharbatla, 2008). Gangadharbatla's research showed that those who have higher need to belong tend to spend more time online. Need to belong refers to a person's sense that they want to be associated with others and to be accepted by them. This variable was measured by asking how much respondents feel treated better online than offline and how much they feel online interactions help them feel better when they are down.

Social Media Use. The survey measured participants' social media use by asking how much time they spend on social networking sites (Facebook, Twitter, YouTube, Foursquare, and Myspace) on an average weekday and weekend day. These were the most popular social networking sites when the survey was in the field (Lenhart et al., 2011; Lenhart, 2012). Participants were asked to indicate how much they agree with several possible reasons for using social networking sites: (i) "to pass time"; (ii) "to communicate with friends"; (iii) "to learn things outside school"; and (iv) "to help me feel better when I am feeling down." 
Communication Methods for Meet-ups and Flash Mobs. Teens were asked how frequently they use certain communication approaches to arrange meet-ups with their friends and to get information about flash mobs. Communication methods included email, text message, Facebook, Twitter, speaking in person, and speaking by phone.

Perceptions of Flash Mobs. The survey included a series of questions aimed at understanding teens' perceptions of flash mobs. First, respondents were asked whether they were familiar with the term "flash mob." Those who said yes to this question were led to a set of questions about flash mobs, which asked whether they have ever participated in a flash mob, how much they might be willing to participate in the future, how they would describe flash mobs, and why they think teens organize flash mobs.

Demographics. A set of demographic questions was included at the end of the questionnaire. Respondents were asked to indicate their age, gender, level of education, race, and household socio-economic status. They were also asked to enter their zip code to ensure that only responses of Kansas City teens were analyzed.

\section{Data analysis}

This study used a path analysis with a series of multiple regression analyses to test the theoretical model presented in Figure 1 and the hypothesized relationships among the variables. A hierarchical method was used in conducting the regression analyses. Gender, race, and socioeconomic status variables were entered first in the regression equations as control variables. Then social psychological variables - social self-efficacy, collective self-esteem, and need to belong — were entered, followed by social media use and intention to participate in a flash mob. Tolerance and Variance Inflation Factor (VIP) statistics were calculated to test for multicollinearity. No significant multicollinarity was identified. 


\section{Results}

\section{Demographic Characteristics of Participants}

A total of 280 teens in Kansas City participated in the survey. This is an acceptable sample size given the fact that parental consent was required for teens under 18 , about $70 \%$ of the respondents, to participate in this study. Most of the respondents were high school students $(89.7 \%)$ with some participation from middle school students $(6.2 \%)$ and college students or high school graduates $(4.1 \%)$. About $68 \%$ of the survey respondents were female and $32 \%$ were male. African Americans were the largest group accounting for 53.3\%, followed by Hispanics (24.2\%) and Caucasians (15.4\%). A little over half of the respondents (53.9\%) described their household socio-economic status as middle class, followed by $30.3 \%$ working class, $13.3 \%$ upper middle class, and $2.5 \%$ upper class. Full demographic breakdowns are shown in Table 1.

\section{Teens' Use of Social Media for Flash Mobs}

More than $80 \%$ of the survey participants reported spending some time on social networking sites everyday (Figure 2). YouTube was the most popular social networking site among youth, followed by Facebook and Twitter. Less than 5\% of the respondents indicated that they used Foursquare or Myspace. As shown in Table 2, communicating with friends was the most important reported reason for youth to use social networking sites $(M=4.99, S D=1.86)$, followed by to pass time $(M=3.80, S D=1.96)$, to learn things outside school $(M=3.45, S D=$ $1.97)$, and to feel better when they are down $(M=2.57, S D=1.93)$.

As shown in Table 3, Facebook $(M=2.25, S D=2.15)$ was the most frequently reported communication method for youth to get information about upcoming flash mobs. Facebook was followed by speaking in person $(M=2.19, S D=1.97)$, text messaging $(M=2.17, S D=2.09)$, speaking by phone $(M=1.67, S D=1.61)$, Twitter $(M=1.59, S D=1.50)$, and email $(M=1.41$, 
$S D=1.14)$. Texting was most popular $(M=5.65, S D=1.94)$ for arranging meet-ups with friends. This is consistent with previous research showing youth's heavy use of text messages (Solecki and Goldschmidt, 2011; Lenhart et al., 2010). Texting was followed by speaking in person $(M=5.44, S D=1.62)$, speaking by phone $(M=4.74, S D=1.86)$, Facebook $(M=3.80$, $S D=2.19)$, Twitter $(M=2.70, S D=2.35)$, and email $(M=2.33, S D=1.85)$.

\section{Teens' Perceptions of Flash Mobs}

Respondents were asked to indicate whether they were familiar with the term flash mob. Of the 260 people who answered this question, $65.4 \%$ said they were familiar with the term and $34.6 \%$ said they were not. The following responses are from those who said they were familiar with flash mob.

As shown in Figure 3, fun (26\%) and random (23.1\%) were the two most popular adjectives selected by respondents saying they were familiar with flash mobs. Other adjectives used to describe flash mobs included spontaneous (20.8\%) and organized (15\%). Only a small proportion of teens described flash mobs as out of control (8.7\%) or violent (6.4\%). For this question, the participants were provided those six adjectives that were identified through our preliminary focus group research and were asked to select all that apply. Asked why they thought teens participated in flash mobs, 35\% said it was to express themselves (Figure 4). To hang out with friends (30.7\%), boredom (27.5\%), to gain attention (24.6\%), and to make new friends (24.3\%) were the other important reasons mentioned. About $20.4 \%$ said there was no particular reason for teens to participate in a flash mob, and $12.5 \%$ said it was because of peer pressure. Multiple responses were permitted for this question.

When asked how likely they were to participate in a flash mob in the future, $38.3 \%$ said likely, $52.2 \%$ unlikely, and $9.7 \%$ were undecided. More specifically, $17.7 \%$ said very likely, 
5.7\% likely, $14.9 \%$ somewhat likely, $9.7 \%$ undecided, $5.7 \%$ somewhat unlikely, $13.1 \%$ unlikely, and $33.1 \%$ very unlikely. In addition, $15.8 \%$ of the respondents said they have participated in a flash mob and $29.9 \%$ said their friends have participated in a flash mob.

\section{Factors Related to Teens' Social Media Use and Participation in a Flash Mob}

Figure 5 summarizes the results of the path analysis of the combined hypotheses. Table 4 shows specific statistics for the variables tested—-standardized coefficients and $t$-statistics for the independent variables and total variance explained and $F$-statistics for the dependent variables.

Hypotheses 1 proposed that teens' social psychological characteristics would influence the amount of time they spend on social networking sites even when controlling for gender, race, and household socio-economic status. Specifically, Hypothesis 1a posited that teens' social selfefficacy would be positively associated with the amount of time they spend on social networking sites. Hypothesis $1 \mathrm{~b}$ posited that teens' collective self-esteem would be positively correlated with the amount of time spent on social networking sites. Hypothesis 1c stated that teens' need to belong would be positively correlated with amount of time spent on social networking sites. The results show that social self-efficacy $(\beta=.05, t=.65, p=$ n.s. $)$ and collective self-esteem $(\beta=-$ $.02, t=-.32, p=$ n.s.) are not significant predictors of teens' use of social media. However, need to belong was a statistically significant predictor of amount of time spent on social networking sites even when controlling for demographic variables $(\beta=.28, t=4.15, p<.001)$. This finding is consistent with previous research on the role of need to belong in social media use (Ledbetter, et al., 2011; Pelling and White, 2009; Valkenburg and Peter, 2008). Thus, Hypothesis 1c is supported, whereas Hypotheses $1 \mathrm{a}$ and $1 \mathrm{~b}$ are not.

Research Question 2 asked how teens' social media use is associated with intention to participate in a flash mob, even when controlling for the demographic variables (gender, race, 
and household socio-economic status) and social psychological variables (social self-efficacy, collective self-esteem, and need to belong). The relationship was not statistically significant $(\beta=$ $-.02, t=-.24, p=$ n.s.). However, a correlation test indicated a strong positive relationship between how much time teens spend on YouTube and their intention to participate in a flash mob in the future $(r=.18, p=.05)$. No statistically significant relationship was found between teens' intention to participate in a flash mob and amount of time spent on other social networks sites (Facebook, Twitter, Foursquare, and MySpace).

Finally, Research Question 3 dealt with teens' social psychological characteristics (social self-efficacy, collective self-esteem, and need to belong) and their intention to participate in a flash mob. Gender, race, and household socio-economic status were controlled for in testing the effects of teens' social psychological characteristics on their reported intention to participate in a flash mob. The results show that teens' social self-efficacy is a significant predictor of their intention to participate in a flash mob $(\beta=.21, t=2.25, p<.05)$. That is, the higher the level of social self-efficacy, the stronger the intention to participate in a flash mob. Correlations between individual items of the social self-efficacy index and intention to participate in a flash mob were also examined. Of the eight items, how well respondents can become friends of other people their age $(r=.20, p<.05)$ and how well they succeed in staying friends with people their age $(r$ $=.29, p<.01)$ showed a significant positive relationship with respondents' intention to participate in a flash mob. In comparison, collective self-esteem $(\beta=-.00, t=-.02, p=\mathrm{n} . \mathrm{s}$. $)$ and need to belong $(\beta=-.00, t=-.06, p=$ n.s. $)$ did not show significant effects on teens' intention to participate in a flash mob in the future. 


\section{Discussion}

This is one of the first empirical studies to examine both teens' perceptions of flash mobs and how teens' use of social media and social psychological characteristics are associated with their reported intention to participate in flash mobs in the future. Studying flash mobs in the context of social media is important because they are an important exemplar of collective action in the networked information age. Understanding the flash mob phenomenon may help us better make sense of and anticipate other forms of collective action in the $21^{\text {st }}$ century. Results of this study have implications for both academic and policy communities with regard to teens' use of social media and collective action as well as youth engagements.

A key result was that among teens who said they knew what a flash mob was, social selfefficacy was a significant predictor of their stated intention to participate in a flash mob even when controlling for gender, race, and household socio-economic status. That is, the higher the level of social self-efficacy, the stronger the stated intention to participate in a flash mob. Social self-efficacy refers to individuals' belief that they are competent in forging new friendships and was measured by items adapted from Zullig et al.'s study (2011) of US adolescents. Teens' intention to participate in a flash mob was also positively correlated with how well they can become friends of other people their age and how well they succeed in staying friends with people their age.

The positive relationship between social self-efficacy and intention to participate in a flash mob suggests that flash mobs may be an important form of collective action by teens in this digitally connected society (Bimer, Flanagin and Stohl, 2012; Earl and Kimport, 2011; Rheingold, 2002). Despite the recent episodes of violence in youth gatherings that were sometimes labeled as flash mobs by the media, this study found that teens knowledgeable about 
flash mobs generally view them as fun and entertaining gatherings that provide an outlet for selfexpression. Thus, as the networked information society grows with an accompanying increasing degree of disintermediation and nonmarket peer production (Benkler, 2006; Castells, 2002), teens may rely more on flash mob-style events to express themselves. It is also possible that a flash mob is a cultural by-product of a shift from dutiful citizenship rooted in responsibility and duty to actualizing citizenship rooted in self-actualization through social expression (Bennett, Wells and Rank, 2009; Bennett, Wells and Freelon, 2011). The tendency for teens to want to meet up and hang out in groups is not new nor is it solely the product of digital technologies. What social and mobile technologies bring to this is the possibility of broader and more effective peer-to-peer coordination among teens, which in turn may result, for example, in teens from different schools assembling together more often and more quickly than would have occurred in the past. Teen behavior will become increasingly unmoored from their very local geography.

The positive correlation between the amount of time spent on YouTube and intention to participate in a flash mob in the future is quite interesting. This possibly indicates a YouTube amplified media effect where teens see certain behaviors and are then more likely to engage in them. As this research did not measure whether the survey participants had watched flash mob videos on YouTube, the results should be interpreted with caution. Still, the positive relationship between the amount of time spent on YouTube and intention to participate in a flash mob is suggestive as it is consistent with previous research showing effects of media consumption on youth's behavior (Pardun, L'Engle and Brown, 2009; Quintelier and Hooghe, 2011). In fact, this finding is in line with the emergence of actualizing citizenship which "favor interactive, networked activities often communicated through participatory media such as videos shared across online networks" (Bennett, Wells and Rank, 2009: 105). The vast adoption of user- 
generated online videos has made entertainment flash mobs popular throughout the world (Goldschmidt, 2011; Joung, 2005). Some flash mob organizers create a video of a proposed public performance of a flash mob so that prospective participants can learn and practice. A social cognitive process involving online videos is an important area to further investigate. A recent Pew survey of teen Internet users (Lenhart, 2012) showed that 27\% of Internet-using teens record and upload video to the Internet, up from 14\% in 2006. In addition, 37\% of teen Internet users reported that they participate in video chats.

This positive relationship between time spent on the YouTube site and intention to participate in a flash mob indicates the importance of engaging teens through video-based interactive channels. In communicating with teens, agencies need to go to the online sphere where those teens are active. City officials and youth leaders need to engage them via YouTube, which is currently the leading video-focused social networking site (YouTube Statistics, 2013). As of February 2013, YouTube has more than 800 million unique visitors each month. Understanding online social behavior of the target audience is key to successful engagement (Li and Bernoff, 2008; Solis, 2010).

Consistent with previous research (Gangadharbatla, 2008), the authors found teens reporting a stronger need to belong also spend more time online. The positive relationship between the two variables was statistically significant even when controlling for gender, race, and household socio-economic status. "Need to belong" was measured by asking how much participants feel treated better online than offline and how much they feel online interactions help them feel better when they are down. This finding indicates lonely teens are more likely to experiment with their identities online, benefitting from the relative anonymity of the Internet in learning how to interact with people (Valenzuela et al, 2009; Valkenburg and Peter, 2008). 
While social networking sites offer diverse features, people are drawn to these sites primarily for personal connections and sharing of activity with a growing number of "friends." Social networking sites respond to youth's need to belong.

No statistically significant relationship was found between teens' collective self-esteem and their reported intention to participate in a flash mob. This makes sense in that flash mobs are generally gatherings of strangers or loose social networks and thus their sense of association or identity with the group may not be as strong as that with their ordinary peer groups. Previous research (Baker, 2009) found that adolescents reporting high group identification and positive collective self-esteem tend to use social networking sites mainly to maintain contact with their closest peer groups and those who showed negative collective self-esteem tend to seek a form of virtual companionship or social compensation through engaging in social networking sites. The flash mob is an interesting case in that it involves both online and offline interactions. Future research should examine mediating variables between collective self-esteem and intention to participate in a flash mob.

There are some limitations of this study that readers should consider as they interpret the findings. First, a larger and more representative sample would have provided more generalizable findings. This study is based on responses from 280 teens with about $15 \%$ of them not responding to some demographic questions. While this is an acceptable sample size given that parental consent was required for teens under 18 to participate in this study, a more effective approach to gathering parental consent forms might have produced more responses. Second, this research includes a higher proportion of females than males and this may have affected some of the results. Finally, the proportion of Caucasian participants is only $15 \%$ and the representation of Asian participants is limited. Future research should study the topic at the national and 
international level. This will allow researchers to investigate whether characteristics of a city or nation may affect relationships between the variables studied in this research.

This research examined teens' use of social media and perspectives on flash mobs by incorporating theories from communication, sociology, and psychology. Flash mobs are an important example of how collective action is initiated, mobilized and spread in this age of online social networking. The results of this study have implications for future academic research on youth, social media, and collective action. In addition, this research provides policy-makers with empirically informed suggestions for dealing with this complex issue of youth participation in flash mobs. 


\section{References}

Barker V (2009) Older adolescents' motivations for social network site use: The Influence of gender, group identity, and collective self-esteem. Cyber Psychology \& Behavior 12: 209-213.

BBC (2012) Olympics tennis: Wimbledon, but not as you know it. Available at: http://www.bbc.co.uk/sport/0/olympics/19043245 (accessed 14 February 2013).

Benkler Y (2006) The wealth of networks: How social production transforms markets and freedom. New Haven, CT: Yale University Press.

Bennett WL, Wells C and Freelon D (2011) Communicating civic engagement: Contrasting models of citizenship in the youth Web sphere. Communication Research 61(5): 835-856.

Bennett WL, Wells C and Rank A (2009) Young citizens and civic learning: Two paradigms of citizenship in the digital age. Citizenship Studies 13(2): 105-120.

Bimer, B, Flanagin, AJ and Stohl C (2012) Collective action in organizations: Interaction and engagement in an era of technological change. New York, NY: Cambridge University Press.

boyd d (2008) Why youth heart social network sites: The role of networked publics in teenage social life. In Buckingham D (Ed.) Youth, identity, and digital media. The John D. and Catherine T. MacArthur Foundation Series on Digital Learning. Cambridge, MA: MIT Press, pp. 119-142.

boyd d and Ellison NB (2008) Social network sites: Definition, history, and scholarship. Journal of Computer-Mediated Communication 13: 210-230. 
Castells M (2004) Informationalism, networks, and the network society: A theoretical blueprinting. In Castells M (Ed.) The network society: A cross-cultural perspective. Northampton, MA: Edward Elgar.

CNN (2010) Flash mob for good. Available at: http://ireport.cnn.com/topics/454082 (accessed 14 February 2013).

Correa T, Hinsely AW and de Zuniga HG (2010) Who interacts on the Web?: The intersection of users' personality and social media use. Computers in Human Behavior 26(2): 247-253.

Davis K (2011) Tensions of identify in a networked era: Young people's perspectives on the risks and rewards of online self-expression. New Media \& Society 14(4): 634-651.

Duggan M and Brenner J (2013) The demographics of social media users - 2012. Pew Research Center's Internet \& American Life Project.

Earl J and Kimport K (2011) Digitally enabled social change: Activism in the Internet age. Cambridge, MA: MIT Press.

Ellison N, Steinfield C and Lampe C (2007) The benefits of Facebook 'friends': Social capital and college students' use of online social network sites. Journal of Computer-Mediated Communication 12(4):1143-1168.

Gangadharbatla H (2008) Facebook me: Collective self-esteem, need to belong, and Internet selfefficacy as predictors of the Igeneration's attitudes toward social networking sites. Journal of Interactive Advertising 8(2): 5-15.

Goldschmidt K (2011) Adolescents texting and twittering: The flash mob phenomena. Journal of Pediatric Nursing 26: 167-169.

Gore G (2010) Flash mob dance and the territorialisation of urban movement. Anthropological Notebooks 16(3): 125-131. 
Hargittai E and Hinnant A (2008) Digital inequality: Differences in young adults' use of the Internet. Communication Research 35(5): 602-621.

Harwood J (1999) Age identification, social identity gratifications, and television viewing. Journal of Broadcasting \& Electronic Media 43: 123-136.

Hlebec V, Manfreda KL and Vehovar V (2006) The social support networks of Internet users. New Media \& Society 8(1): 9-32.

Hundley HL and Shyles L (2010). US teenagers' perceptions and awareness of digital technology: a focus group approach. New Media \& Society, 12(3): 417-433.

Ito M, Baumer S, Bittani M, boyd d and Cody R (2010) Hanging out, messing around, and geeking out: Kids living and learning with new media. The John D. and Catherine T. MacArthur Foundation Series on Digital Learning. Cambridge, MA: MIT Press.

Joung Y (2005) Flash mobs: The younger generation declares its cultural independence. Koreana 19: 74-77.

Kahn R and Kellner D (2004) New media and internet activism: form the 'Battle of Seattle' to blogging. New Media \& Society. 6(1): 87-95.

Kaplan AM and Haenlein M (2010) Users of the world, united! The challenges and opportunities of Social Media. Business Horizons 53: 59-68.

Ledbetter A, Mazer J, DeGroot J, Meyer K, Mao Y and Swafford B (2011) Attitudes toward online social connection and self- disclosure as predictors of Facebook communication and relational closeness. Communication Research 38(1): 27-53.

Lee K (2011). London riots, twitter, news coverage on twitter, social media. Available at: http://www.lexisnexis.com/community/lexishub/blogs/legaltechnologyandsocialmedia/ar 
chive/2011/08/09/flash-mob-riots-crime-in-the-age-of-twitter.aspx (accessed 9 August 2011).

Lenhart A, Purcell K, Smith A and Zickuhr K (2010) Social media \& mobile internet use among teens and young adults. Pew Internet \& American Life Project: 1-37.

Lenhart A, Madden M, Smith A, Purcell K, Zickuhr K and Rainie L (2011) Teens, kindness and cruelty on social network sites. Pew Research Center's Internet \& American Life Project: 1-86.

Lenhart A (2012) Teens \& online video. Pew Research Center's Internet \& American Life Project: 1-13.

Li C and Bernoff J (2008) Groundswell: Winning in a world transformed by social technologies. Boston, MA: Harvard Business Press.

Madden M, Lenhart A, Duggan M , Cortesi S and Gasser U (2013) Teens and technology 2013. Pew Research Center's Internet \& American Life Project.

Molnar V (2009) Reframing public space through digital mobilization: The case of flash mobs. Paper presented at the American Sociological Association Annual Meeting, San Francisco, CA.

Palfrey J and Gasser U (2008) Born digital: Understanding the first generation of digital natives. New York, NY: Basic Books.

Pardun CJ, L'Engle KL and Brown JD (2009) Linking exposure to outcomes: Early adolescents' consumption of sexual content in six media. Mass Communication and Society 8(2): 7591.

Pelling E and White K (2009) The theory of planned behavior applied to young people's use of social networking Web sites. CyberPsychology \& Behavior 12: 755-759. 
Pickard VW (2008) Cooptation and cooperation: institutional exemplars of democratic internet technology. New Media \& Society 10(4): 625-645.

Purcell, K. (2012, July). Teens 2012: Truth, trends, and myths about teen online behavior. ACT Enrollment Planners Annual Conference.

Quintelier E and Hooghe M (2011) Television and political participation among adolescents: The impact of television viewing, entertainment and information preferences. Mass Communication and Society 14(5): 620-642.

Solis B (2011) Engage: The Complete Guide to Brands and Businesses to Build, Cultivate, and Measure Success in the New Web. New Jersey: John Wiley \& Sons, Inc.

Urbina I (2010). Mobs are born as word grows by text message. The New York Times. Available at: http://www.nytimes.com/2010/03/25/us/25mobs.html?_r=1 (accessed 24 March 2010)

Valenzuela S, Park N and Kee KF (2009) Is there social capital in a social network site?:

Facebook use and college students' life satisfaction, trust, and participation. Journal of Computer-Mediated Communication 14(4): 875-901.

Valkenburg PM and Peter J (2008) Adolescents' identity experiments on the Internet:

Consequences for social competence and self-concept unity. Communication Research 35(2): 208-231.

Valkenburg PM, Schouten AP and Peter J (2005) Adolescents' identity experiments on the Internet. New Media \& Society 7: 383-402.

Walker R. (2003). We're all connected? The New York Times. Available at: http://www.nytimes.com/2003/08/24/magazine/24WWLN.html (accessed 24 August 2003). 
Wasik B (2011) \#Riot: Self-organized, hyper-networked revolts - Coming to a city near you.

Wired Magazine. Available at http://www.wired.com/magazine/2011/12/ff_riots/ (accessed 16 December 2011).

Zeitz KM, Tan HM and Zeitz CJ (2009) Crowd behavior at mass gatherings: A literature review. Prehospital Disaster Med 24(1): 32-38.

Zullig KJ, Teoli DA and Valois RF (2011) Evaluating brief measure of social self-efficacy among U.S. adolescents. Psychological Reports 109(3): 907-920. 


\section{Table 1}

\section{Characteristics of Survey Participants}

\begin{tabular}{|c|c|c|c|}
\hline Variable & Value & Count & Percent \\
\hline \multirow[t]{3}{*}{ Gender } & Female & 163 & $67.9 \%$ \\
\hline & Male & 77 & $32.1 \%$ \\
\hline & Total & 240 & $100 \%$ \\
\hline \multirow[t]{4}{*}{ Education } & High school student & 218 & $89.7 \%$ \\
\hline & Middle school student & 15 & $6.2 \%$ \\
\hline & $\begin{array}{c}\text { College student or high school } \\
\text { graduate }\end{array}$ & 10 & $4.1 \%$ \\
\hline & Total & 243 & $100 \%$ \\
\hline \multirow[t]{8}{*}{ Race } & African American & 128 & $53.3 \%$ \\
\hline & Hispanic & 58 & $24.2 \%$ \\
\hline & Caucasian & 37 & $15.4 \%$ \\
\hline & Asian/Pacific Islander & 7 & $2.9 \%$ \\
\hline & Other & 7 & $2.9 \%$ \\
\hline & Native American & 2 & $.8 \%$ \\
\hline & Middle Easterner & 1 & $.4 \%$ \\
\hline & Total & 240 & $100 \%$ \\
\hline Socio-economic & Middle class & 130 & $53.9 \%$ \\
\hline \multirow[t]{4}{*}{ status } & Working class & 73 & $30.3 \%$ \\
\hline & Upper middle class & 32 & $13.3 \%$ \\
\hline & Upper class & 6 & $2.5 \%$ \\
\hline & Total & 241 & $100 \%$ \\
\hline
\end{tabular}




\section{Table 2}

\section{Reasons for Youth Using Social Networking Sites}

\begin{tabular}{lcccc}
\hline Variable & Ranking & $M$ & $S D$ & $N$ \\
\hline To communicating with friends & 1 & 4.99 & 1.86 & 269 \\
To pass time & 2 & 3.80 & 1.96 & 269 \\
To learn things outside school & 3 & 3.45 & 1.97 & 269 \\
To feel better when they are down & 4 & 2.57 & 1.93 & 269
\end{tabular}

Note. Respondents were asked to indicate on a 7-point scale $(1=$ not important at all, $7=$ extremely important) the importance to them of each of the following reasons for using social media sites. 


\section{Table 3}

\section{Communication Methods for Meet-ups and Flash Mobs}

\begin{tabular}{lcccccccc}
\hline \multicolumn{7}{c}{ Meet-ups } & \multicolumn{7}{c}{ Flash Mobs } \\
\hline Variable & Ranking & $M$ & $S D$ & $N$ & Ranking & $M$ & $S D$ & $N$ \\
\hline Text messages & 1 & 5.65 & 1.94 & 268 & 3 & 2.17 & 2.09 & 170 \\
Speaking in person & 2 & 5.44 & 1.62 & 269 & 2 & 2.19 & 1.97 & 172 \\
Speaking by phone & 3 & 4.74 & 1.86 & 268 & 4 & 1.67 & 1.61 & 170 \\
Facebook & 4 & 3.80 & 2.19 & 269 & 1 & 2.25 & 2.15 & 172 \\
Twitter & 5 & 2.70 & 2.35 & 267 & 5 & 1.59 & 1.50 & 171 \\
Email & 6 & 2.33 & 1.85 & 261 & 6 & 1.41 & 1.14 & 171 \\
& & & & & & & & \\
\hline
\end{tabular}

Note. Respondents were asked to indicate on a 7 -point scale $(1=$ never, $7=$ almost always $)$ how frequently they use each of the communication methods to arrange meet-ups and to get information about upcoming flash mobs. 


\section{Table 4}

\section{Results of multiple regression analyses}

\begin{tabular}{|c|c|c|c|c|c|c|}
\hline Dependent variable & Independent variable & $\beta$ & $t$ & $R^{2}$ & $\Delta R^{2}$ & $F$ \\
\hline \multirow[t]{3}{*}{ Social media use } & Social self-efficacy & .05 & .65 & .14 & .08 & $6.05 * * *$ \\
\hline & Collective self-esteem & -.02 & -.32 & & & \\
\hline & Need to belong & $.28 * * *$ & 4.15 & & & \\
\hline \multirow[t]{3}{*}{ Flash mob participation } & Social self-efficacy & $.21 *$ & 2.25 & .08 & .04 & 2.08 \\
\hline & Collective self-esteem & -.00 & -.02 & & & \\
\hline & Need to belong & -.00 & -.06 & & & \\
\hline \multirow[t]{4}{*}{ Flash mob participation } & Social self-efficacy & $.20 *$ & 2.06 & .07 & .00 & .06 \\
\hline & Collective self-esteem & -.00 & -.03 & & & \\
\hline & Need to belong & .02 & .23 & & & \\
\hline & Social media use & -.02 & -.24 & & & \\
\hline
\end{tabular}

Note. Gender, race, and household socio-economic status were controlled for in all analyses.

$* p<.05, * * p<.01, * * * p<.001$. 

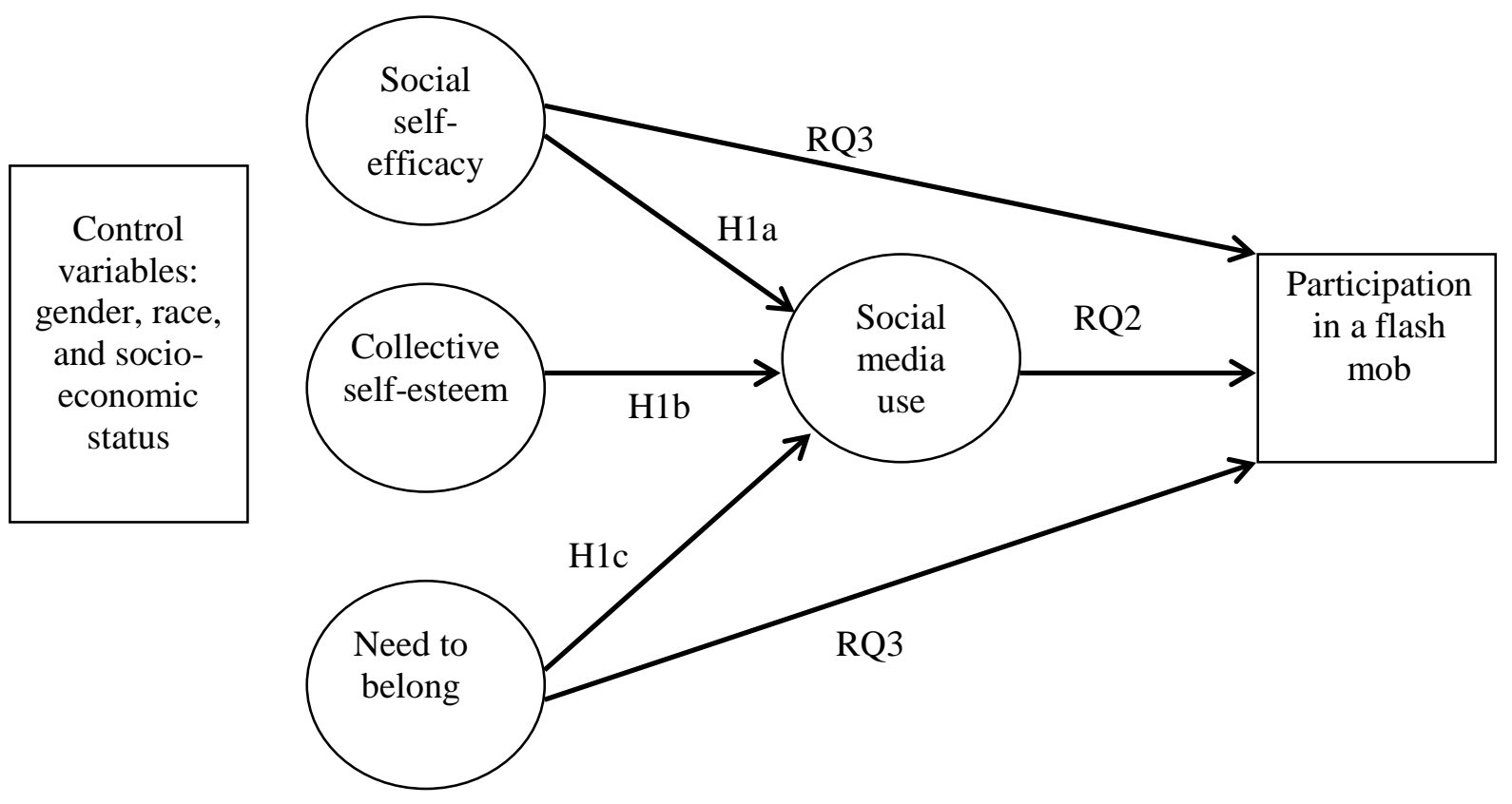

Figure 1. Hypothesized model of the relationships between social psychological variables, social media use, and intention to participate in a flash mob 
Social Media \& Collective Action 35

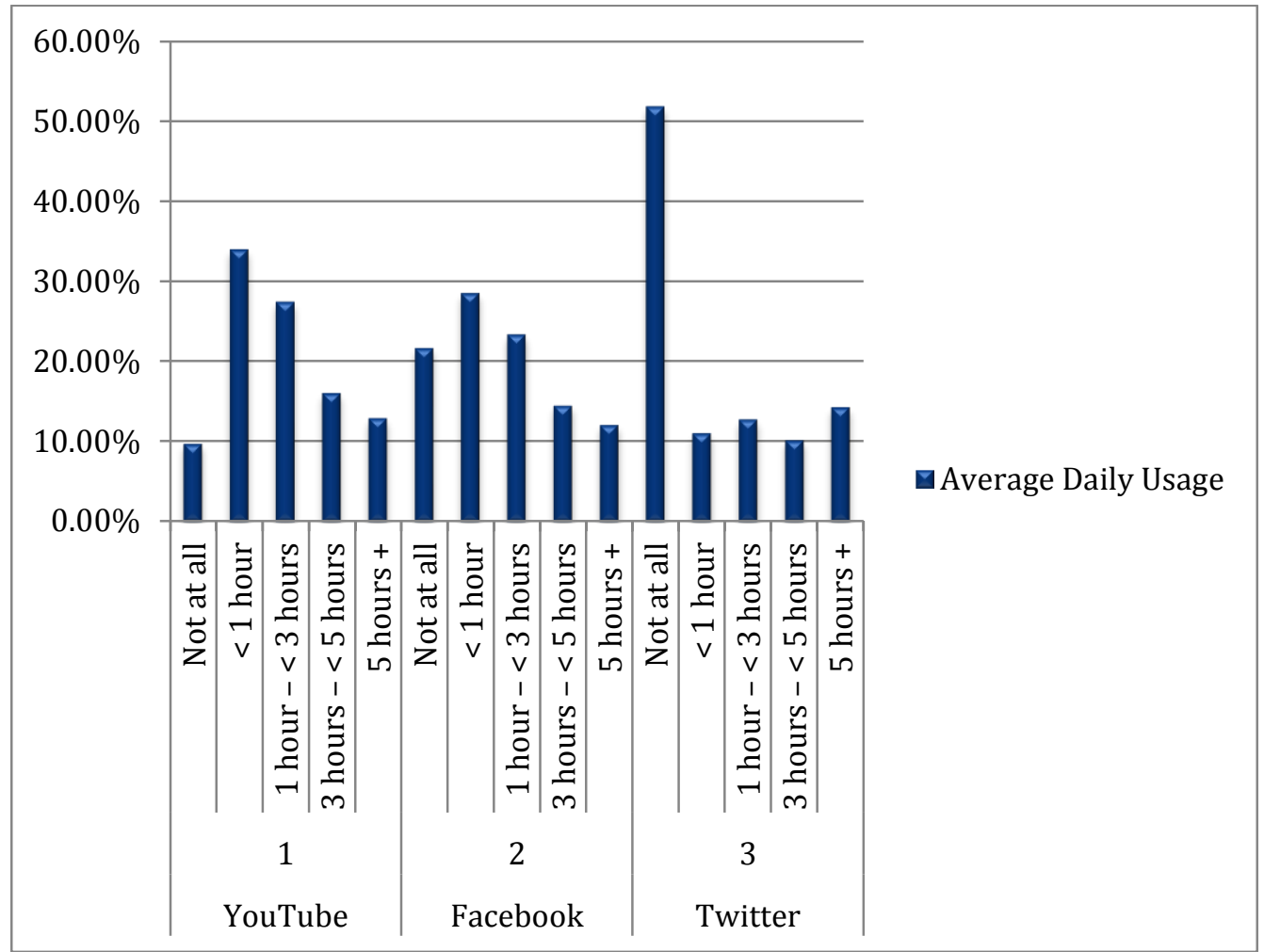

Figure 2. Use of social networking sites 


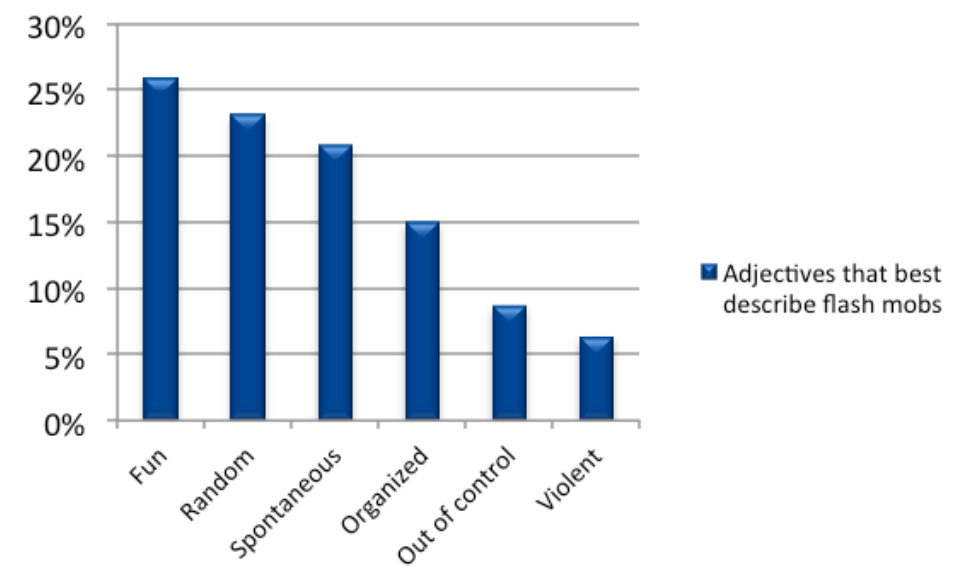

Figure 3. Adjectives that best describe flash mobs

Note. For this survey question, respondents were asked to choose all that apply. 


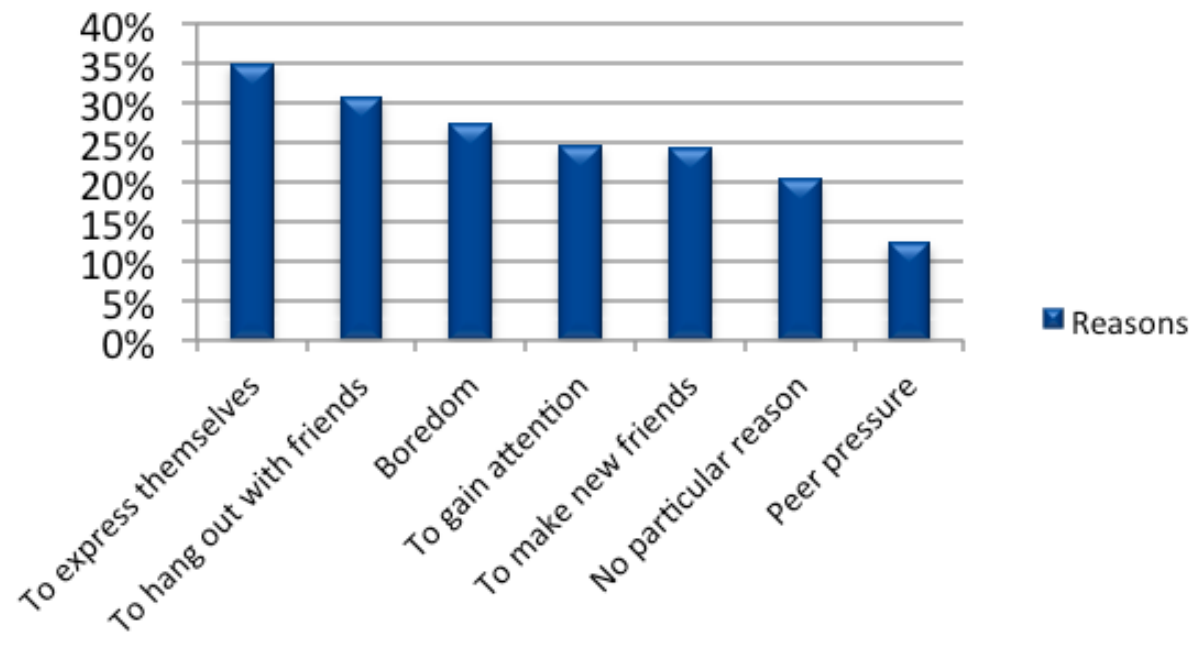

Figure 4. Reasons for participating in a flash mob

Note. For this survey question, respondents were asked to choose all that apply. 

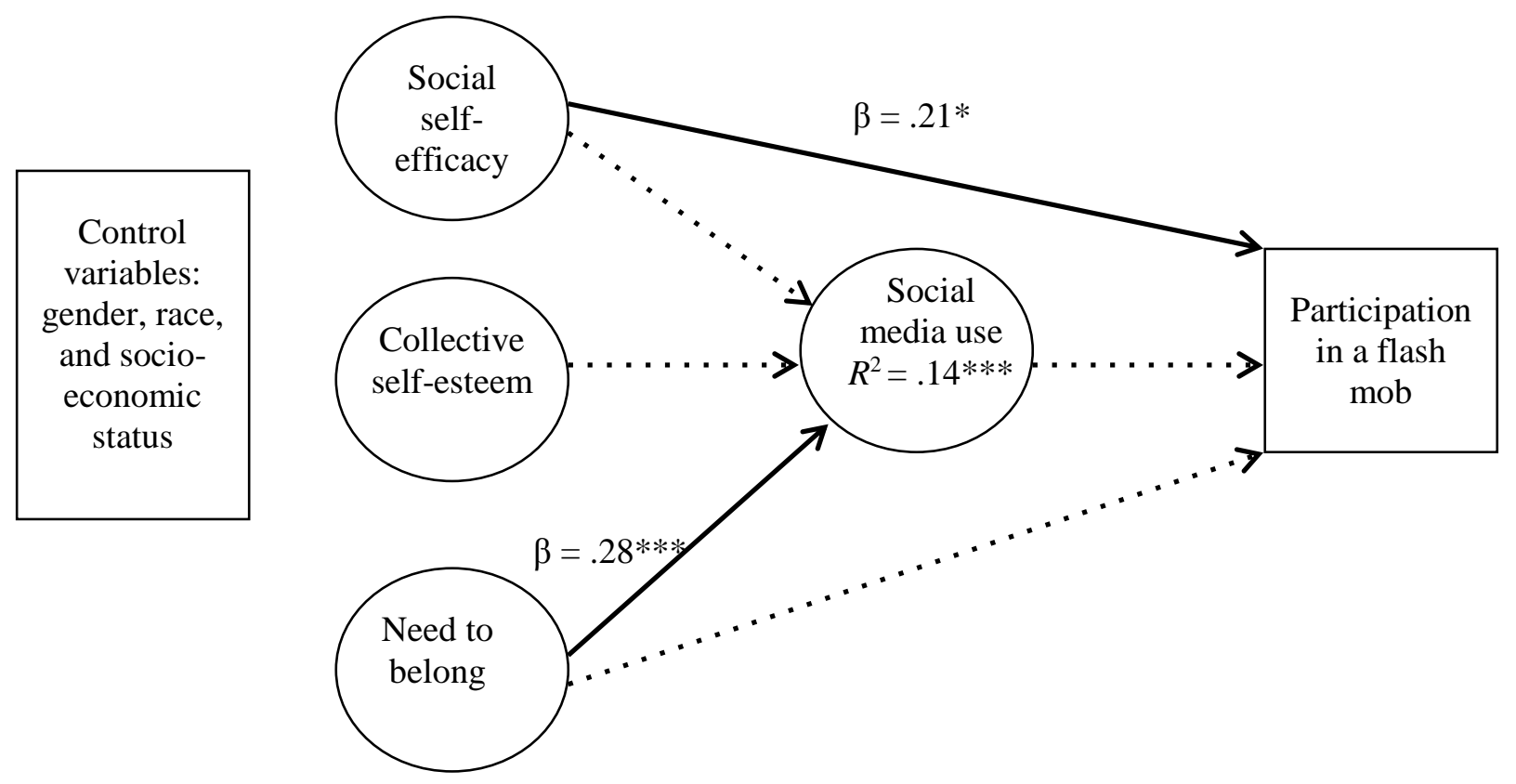

Figure 5. Path analysis results for the relationships between social psychological variables, social media use, and intention to participate in a flash mob

Note: Dotted lines indicate non-significant paths.

$* p<.05, * * p<.01, * * * p<.001$. 